\title{
Simulation of Water Supply in The City of Lima For the Period 2020- 2050 Using the WEAP Platform
}

\author{
José Reynaga, Jorge Cornelio, Manuel Collas \\ University of Applied Sciences (UPC) \\ Spring Extension 2390, Lima, Peru \\ u201623438@upc.edu.pe; u201220255@upc.edu.pe; pccimol@upc.edu.pe
}

\begin{abstract}
Summary - The objective of this study has been to develop a hydrological model in the WEAP platform, to know the water coverage of the water supply of the city of Lima in a current scenario (2020), in the short term 2025, medium term (2035) and long term term (2050). The WEAP (Water Assessment and Planning System) model has been calibrated and validated with the historical records of the Rímac, Chillón and Lurín rivers, which have information from the 1965-2019 period. Currently, the supply of drinking water to the city of Lima comes mainly from the Rímac River, with an average flow of $18.63 \mathrm{~m} 3 / \mathrm{s}$ and in the dry season it is complemented by the exploitation of groundwater from the Rímac, Lurín and Chillón Aquifers. with a volume of $287 \mathrm{MMC}$ / year. It is important to indicate that the water resources of the Rímac River are complemented by the contributions of the Macapomacocha I, III and IV projects that contribute a volume of 243.5 MMC / year and the contributions of the Graton tunnel are $158 \mathrm{MMC}$ / year. From the simulations carried out, it is concluded that there is currently a water deficit of $182 \mathrm{MMC} /$ year and a coverage of $81.8 \%$.
\end{abstract}

Keywords: Weap, Simulation, water supply, water coverage, water deficit.

\section{Introduction}

Currently, the city of Lima has a water deficit of $5.77 \mathrm{~m} 3$ / s. The Rímac River is the main source of water supply, but $75 \%$ of its annual mass of availability is concentrated in the rainy season (January to April), and a large part of this volume of water is lost in the Pacific Ocean, because the Sedapal water supply company has limitations to capture in this period; For this reason, the water supply for the city of Lima in the dry season (May to December) decreases dramatically, and the water demand of 10,000,000 inhabitants cannot be met; For this reason, it is complemented by the exploitation of underground water from the aquifers of the neighboring basins of Lurín and Chillón, with an approximate volume of $210 \mathrm{MMC} / \mathrm{year}$.

The problem of water supply is deficient in Latin America, as indicated in "Population growth and effects of climate variability" [1]. The inequality between supply and demand has caused various problems for the population in water consumption; However, due to the greater demand for water in urban areas, as well as the contamination of the resource, the discharge of wastewater is added, which receives insufficient treatment; For this reason, a hydrological simulation 20112050 was carried out using the WEAP platform in the Aipe river basin located in Colombia, Huila, which allowed simulating its hydrological behavior for the period 1980-2011, resulting in a Nash coefficient of 0.75 , which means high reliability [2].

In Peru, the construction of dams is required, because the water availability of the rivers is concentrated in the period (January to March); For this reason, "the practical applications of Hydrology are found in tasks such as the design and operation of hydraulic structures, water supply, irrigation, hydroelectric generation, flood control, sediment control, among others. The Role of Applied Hydrology is to help analyze the problems related to these tasks and provide a guide for the planning and management of hydraulic resources "[3].

Proposals for the construction of new dams in Peru are not viewed with enthusiasm, due to costs and economic indicators; For example, in southern Peru, a hydrological-economic analysis of existing and projected dams has been carried out, concluding that the storage cost of a cubic meter of water $(1 \mathrm{~m} 3)$ is nine and a half dollars $(\$ 9.5 / \mathrm{m} 3)$, as they are relatively high-altitude dams for a low storage volume due to the rugged topography [4].

Faced with this problem, the water balance has been made for the following scenarios: Current (Balance to 2020), short term (Balance to 2025), medium term (Balance to 2035) and long term (Balance to 2050), and it has been quantified the water deficit in volume and level of coverage, in order to know the water deficit for population use in the city of Lima over time. 


\section{Materials and Methods}

\subsection{Description of the Hydrological Model Weap}

The WEAP (Water Evaluation And Planning System) model is a hydrological modeling tool for planning and distribution of water, which can be applied at different scales, from small hydrographic basins to large basins; On the other hand, the WEAP platform has a wide user base around the world and is available in different languages, including Spanish [5]. This tool incorporates subroutines to represent the calculation of supply, demand, water deficit, runoff, water requirements for crops and population use, and on this occasion, it has been applied to know the behavior of current water supply and demand, in the short term (2025), medium term (2035) and long term (2050).

\subsection{Collection of Meteorological Information and Records}

The need for Data and information are of vital importance, as stated in the "Report of the International Conference on Water and the Environment"'(CIAMA), held in Dublin in January 1992 (United Nations, 1992a), where it offers a convincing assessment of the importance of water resources for the global environment and for the planet's economy. Their specific policy statements very effectively underline the role that hydrological services should play in achieving sustainable development goals [6].

To carry out a hydrological study, it is necessary to collect historical records of all hydrological variables, such as: discharges, precipitation, relative humidity, wind speed and hours of sunshine [7].In the present study, the hydrological simulation has been carried out, taking into consideration the water supply of the Rímac River and the exploitation of groundwater from the Lurín and Chillón aquifers and the demand for water in the period (2020-2050). The tool used is the WEAP (Water Evaluation And Planning System) platform, which has made it possible to carry out a hydrological balance in volume (MMC / year) and at coverage level (\%), for which entry to the database has been required. of data from the aforementioned software, the historical records of precipitation, temperature, relative humidity, wind speed and discharges for the period 1964-2014, for the generation of runoff, which has been calibrated in the hydrometric stations of Chosica (Rímac River), Obrajillo (Chillón) river) and Manchay bridge (Lurín river).

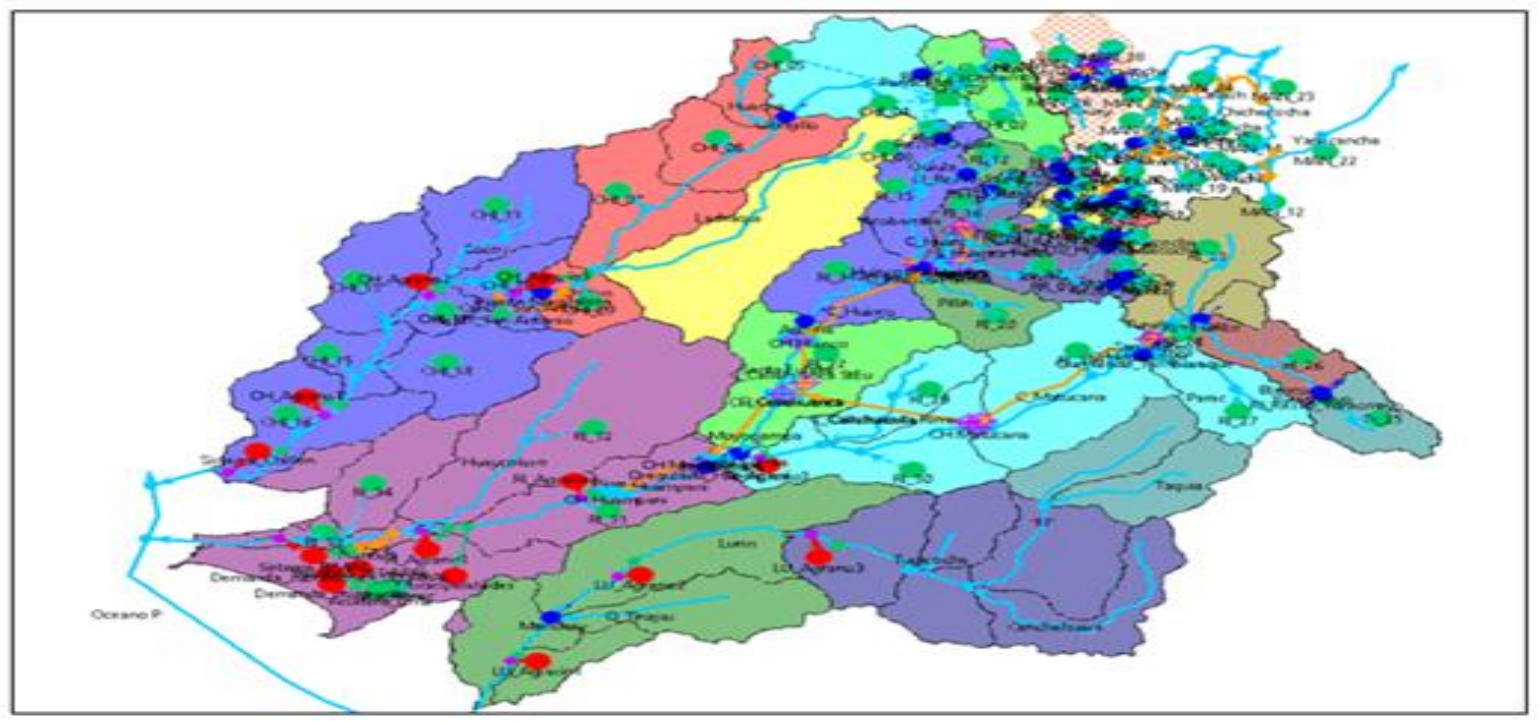

Fig. 1. Hydrological model in Weap Platform for water supply to the city of Lima. Own source 


\subsection{Weap Platform Application Method}

The model used to estimate runoff has been the (Soil Moisture Method), which represents the dynamics of the passage of water in two layers of soil, in the upper layer evapotranspiration is calculated considering rainfall and irrigation in agricultural and non-agricultural lands, and in the lower layer what is related to the base flow; This method requires soil parameters and a detailed climatic characterization to simulate the mentioned processes [8].

\subsection{Approximation Equations of the Hydrological Simulation Model}

The components of the hydrological balance of the WEAP model are: precipitation, infiltration, surface runoff, underground runoff (that is, interflow) and base flow as presented in Figure 2. To estimate these components in each of the basic spatial units named ( Basins or Basin Zones), climatological data and vegetation cover have been used.

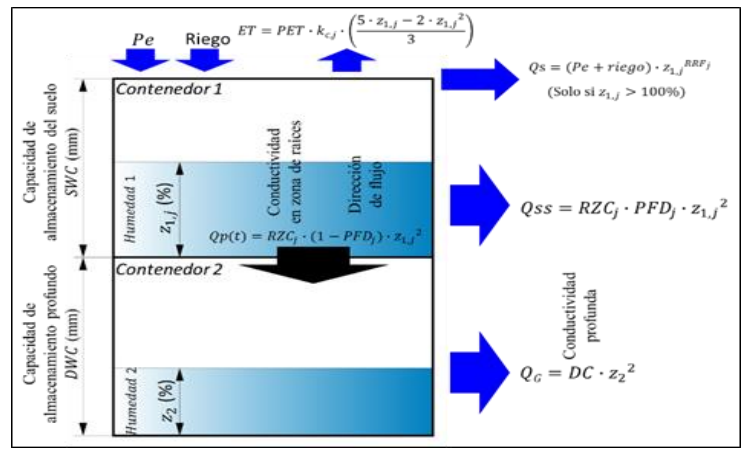

Fig. 2.Center for Global Change-Catholic University of Chile, Stockholm Environment Institute, 2009. Methodological Guide - WEAP Model of Hydrological and Water Resources Modeling. Own source

A basin unit can be divided into several elements that represent different uses and types of land. A water balance has been calculated for each area $\mathrm{j}$ of the $\mathrm{N}$ considered. It is assumed that the climate is uniform in each discretized area and the water balance is given by the following equation $\mathrm{N}^{\circ} 01$ :

$$
R d_{j} \frac{d z_{1, j}}{d t}=P e(t)-P E T(t) \cdot k_{c, j}(t) \cdot\left(\frac{5 \cdot z_{1, j}-2 \cdot z_{1, j}^{2}}{3}\right)-P e(t) \cdot z_{1, j}{ }^{R} F_{j}-P F D_{j} \cdot R Z C_{j} \cdot z_{1, j}{ }^{2} \cdot\left(1-P F D_{j}\right) \cdot R Z C_{j}
$$

Where:

$\mathrm{z} 1, \mathrm{j} \varepsilon[0,1]:$ It is the relative storage of water in the soil, it is a fraction of the total effective water storage in the root layer in the zone

$\mathrm{Rd} \mathrm{j}(\mathrm{mm})$ : Water retention capacity in the soil of a determined area $\mathrm{j}(\mathrm{mm})$.

Pe: Effective precipitation in $(\mathrm{mm})$.

PET (t): Potential evaporation $(\mathrm{mm})$.

$\mathrm{Kc}, \mathrm{j}$ : Coefficient of cultivation of a certain area.

RRFj: Runoff resistance factor for the determined area $j$ that depends on the land cover. Higher values of this factor result in more evaporation and less runoff from the basin.

Pe $(t) z_{-}(1, j) \wedge$ RRFj: Surface runoff.

PDF jk s, j z1, j 2: First layer interflow

PFD j: Partition coefficient that 'divides the vertical and horizontal flow direction.

RZC s, j: saturated hydraulic conductivity of the root zone of area $\mathrm{J}$ ( $\mathrm{mm} /$ time).

The base flow of the second layer, in cases where there is no groundwater node, is calculated with the following expression No. 02: 


$$
D W C \frac{d z_{2}}{d t}=\sum_{j=1}^{N}\left(1-P F D_{j}\right) \cdot R Z C_{j} \cdot z_{1, j}{ }^{2}-D C \cdot z_{2}{ }^{2}
$$

Where:

DWC - Deep Top Storage Preparation

DC: Conductivity in the deep zone ( $\mathrm{mm} /$ time), which is given as a unique value for the sub-basin.

\subsection{Calibration, Validation and Evaluation of the Hydrological Model}

For the calibration and validation of the WEAP hydrological model, the following statistical parameters have been selected: Absolute mean error, Mean square error, Bias (Bias\%), Nash-Sutcliffe coefficient, Mean relative error, Mean square error relative to the mean and Mean square error, which have been applied in calibration and validation. The parameters considered in the hydrological model are: Kc (cultivation coefficient), SWC (field capacity), DWC (Deep soil capacity), RRF (runoff resistance factor), KS (conductivity in the root zone), KD (deep zone conductivity) and Pfd (flow direction), whose values are presented in Table 1

Table 1. WEAP model parameters. Own source

\begin{tabular}{lcccc}
\hline Yam & SWCN $(\mathrm{mm})$ & $\mathrm{Ks}(\mathrm{mm} / \mathrm{month})$ & $\mathrm{RRF}$ & Z1 $(\%)$ \\
\hline Wetland & 700 & 140 & 2.25 & 30 \\
Pajonal & 600 & 110 & 1.15 & 30 \\
Scrub & 600 & 110 & 1.15 & 30 \\
Cardonal & 250 & 80 & 1.25 & 30 \\
Desert & 100 & 80 & 1.75 & 30 \\
Farming & 300 & 110 & 1.75 & 30 \\
High Andean area & 700 & 110 & 0.75 & 30 \\
Urban area & fifty & 80 & 1.75 & 30
\end{tabular}

\begin{tabular}{lc}
\hline Parameter & Hydrographic unit \\
\hline DWC (mm) & 1200 \\
Kd (mm / month) & 300 \\
Pfd & 0.6 \\
Z2 (\%) & 30
\end{tabular}

\section{Analysis of Results}

\section{3.1 Calibration, Validation and Evaluation of the Weap Model}

Calibration and validation has been carried out by comparing the simulated and recorded values at the hydrometric stations of Obrajillo (Chillón), Puente Manchay (Lurín) and Chosica (Rímac), the results of which are presented in Tables 2 and 3 .

Table 2. Calibration of the Weap Model in the hydrometric stations of the Lurín, Rímac and Chillón rivers. Own source

\begin{tabular}{|l|c|c|c|c|c|c|c|c|c|c|c|c|c|}
\hline Description & Jan & Feb & Sea & Apr & may & Jun & Jul & Aug & Sep & Oct & Nov & Dec & Mean \\
\hline Lurin river simulated & 5.84 & 10.88 & 13.32 & 6.05 & 2.60 & 1.12 & 0.88 & 0.65 & 0.92 & 1.22 & 1.32 & 2.41 & 3.93 \\
\hline Lurin river (Gauge) & 6.63 & 11.27 & 13.78 & 7.97 & 2.84 & 1.03 & 0.76 & 0.51 & 0.45 & 0.56 & 1.40 & 3.67 & 4.24 \\
\hline Rmac river simulated & 38.33 & 52.46 & 57.29 & 37.18 & 23.81 & 19.84 & 16.46 & 18.08 & 20.21 & 22.49 & 23.94 & 29.60 & 29.97 \\
\hline Rimac river (Gauge) & 37.04 & 52.62 & 60.68 & 39.03 & 23.65 & 20.10 & 18.81 & 19.02 & 18.40 & 18.91 & 20.60 & 25.67 & 29.54 \\
\hline Chillon river Simulated & 7.16 & 9.91 & 10.07 & 6.06 & 3.24 & 2.41 & 1.95 & 1.90 & 2.25 & 3.00 & 3.39 & 4.71 & 4.67 \\
\hline Chillon river (gauge) & 6.79 & 9.83 & 9.91 & 6.66 & 3.43 & 2.59 & 2.24 & 2.20 & 2.44 & 3.18 & 3.45 & 4.59 & 4.78 \\
\hline
\end{tabular}


Table 3. Validation of the Weap Model in the hydrometric stations of the observed with the simulated Weap Own Source

\begin{tabular}{|l|l|l|l|l|l|l|l|l|l|l|l|l|l|}
\hline Description & Jan & Feb & Sea & Apr & may & Jun & Jul & Aug & Sep & Oct & Nov & Dec & Mean \\
\hline Lurin river simulated & 5.65 & 11.30 & 13.12 & 7.45 & 2.56 & 1.15 & 0.86 & 0.68 & 0.64 & 0.78 & 1.48 & 2.85 & 4.04 \\
\hline Lurin river (Gauge) & 5.95 & 10.89 & 12.85 & 8.10 & 2.87 & 0.98 & 0.74 & 0.49 & 0.47 & 0.58 & 1.37 & 3.45 & 4.06 \\
\hline Rimac river simulated & 31.99 & 45.34 & 49.99 & 32.45 & 24.07 & 22.77 & 19.89 & 22.14 & 23.22 & 24.70 & 24.95 & 27.32 & 29.07 \\
\hline Rímac river (Gauge) & 40.86 & 55.44 & 64.54 & 45.88 & 26.90 & 23.34 & 22.77 & 22.60 & 23.15 & 23.49 & 25.76 & 30.33 & 33.75 \\
\hline Chillon river Simulated & 8.30 & 10.49 & 12.70 & 8.18 & 3.37 & 2.03 & 1.67 & 1.61 & 1.93 & 2.52 & 3.35 & 5.50 & 5.14 \\
\hline Chillon river (gauge) & 7.16 & 9.91 & 10.07 & 6.06 & 3.24 & 2.41 & 1.95 & 1.90 & 2.25 & 3.00 & 3.39 & 4.71 & 4.67 \\
\hline
\end{tabular}

Figures 3, 4 and 5 show the simulated and recorded hydrographs of the Chillón, Rímac and Lurín rivers for the period (1991-2015), a similar analysis has been carried out for the validation period of the period (1965-1990)

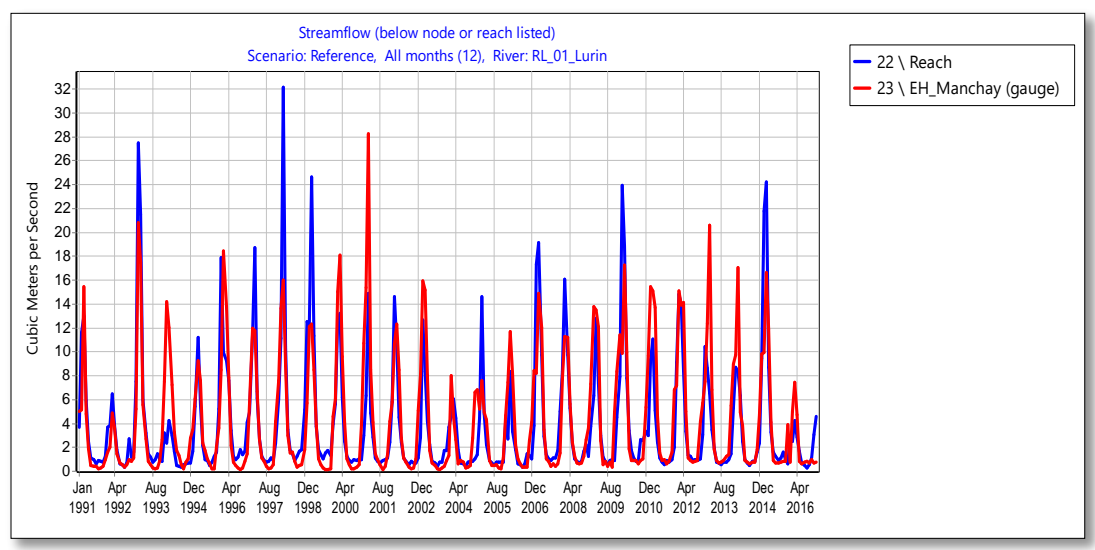

Fig. 3. Comparison of the simulated and recorded hydrograph of the Lurín River at the Manchay station

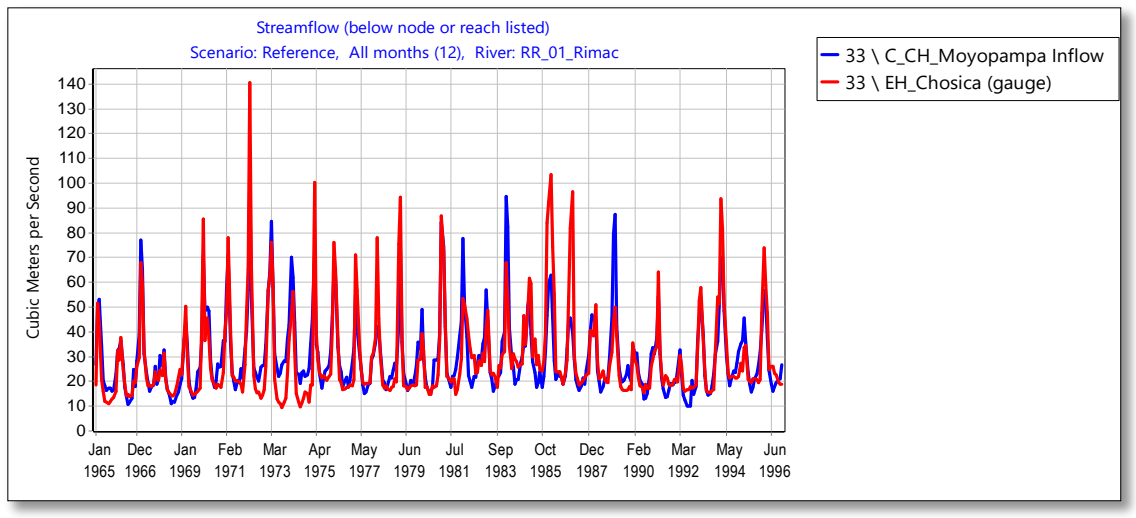

Fig. 4. Comparison of the simulated and recorded hydrograph of the Rímac River at Chosica station 


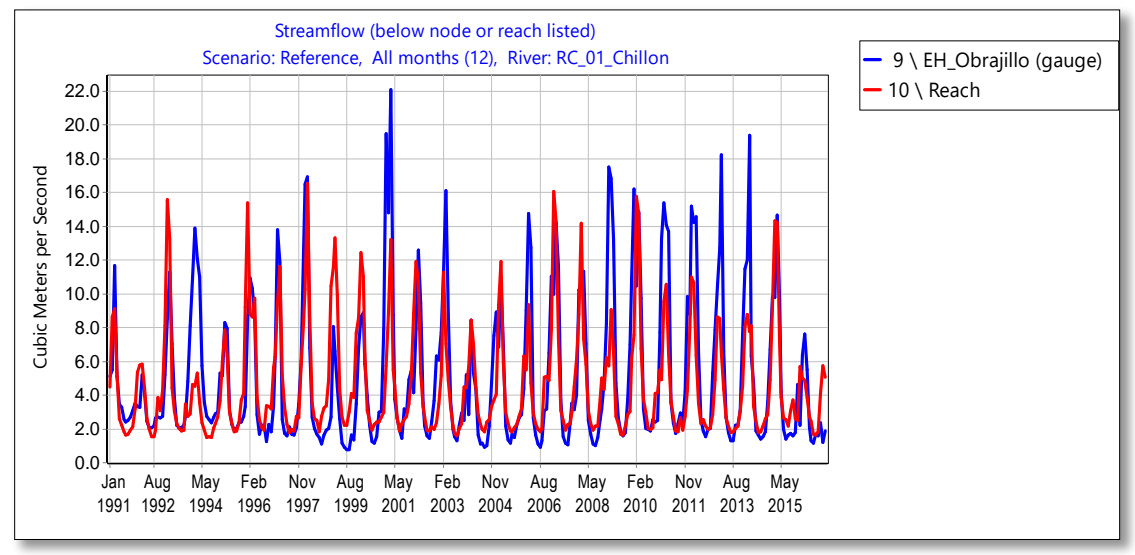

Fig. 5. Comparison of the simulated and recorded hydrograph of the Chillón River at Obrajillo station

\subsection{Population demand and consumption of water through the Weap platform}

To calculate the population demand for water, a population growth rate of $1.2 \%$ and a population of $9,485,405$ inhabitants corresponding to the last census of 2017 have been taken, for which the Weap's "Expression Builder" has been used [9 ]. Table 4 and 5 show the values of the population growth and the demand for water for the years 2025,2035 and 2050 and in Figures 6 and 7 their corresponding graphs.

Table 4. Population growth in the periods (2020-2050) Own source

\begin{tabular}{lcccl}
\hline Years & 2020 & 2025 & 2035 & 2050 \\
\hline Population & $9^{\prime} 830,994$ & $10^{\prime} 435,181$ & $11^{\prime} 757,232$ & $14^{\prime} 060,889$
\end{tabular}

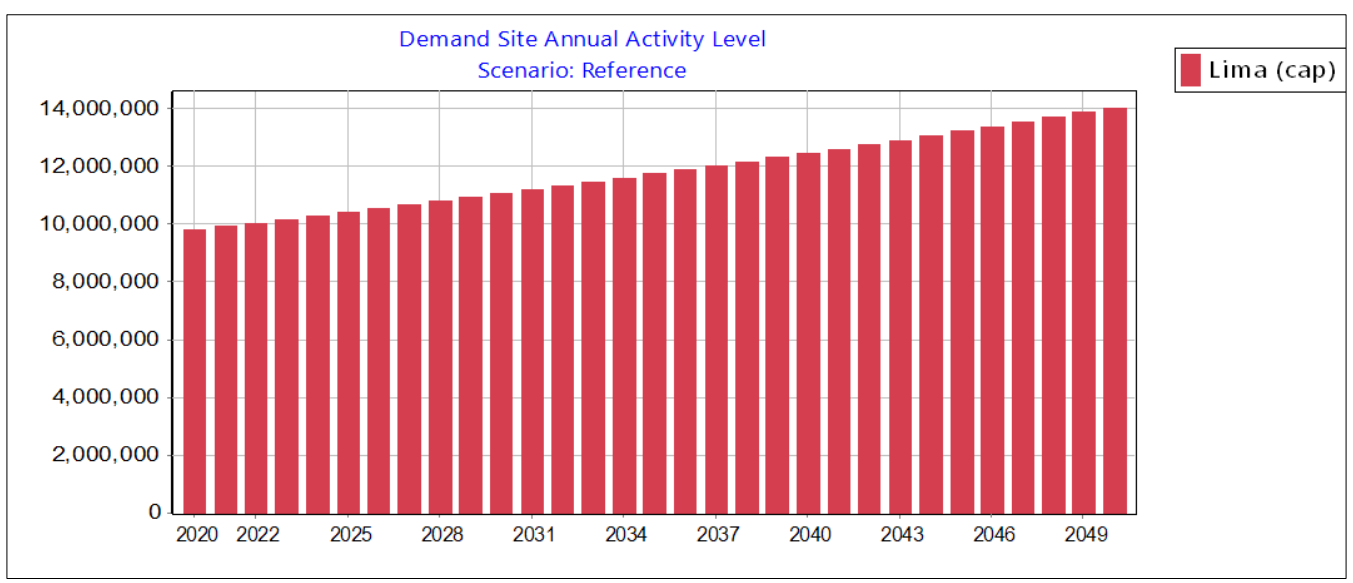

Fig. 6. Population growth in the periods (2020-2050) Own source

Table 5. Demand for water consumption MMC / year (2020-2050) Own source 


\begin{tabular}{lcccc}
\hline Years & 2020 & 2025 & 2035 & 2050 \\
\hline $\begin{array}{l}\text { Volume (MMC / } \\
\text { year) }\end{array}$ & 897.1 & 952.20 & 1072.80 & 1283.10
\end{tabular}

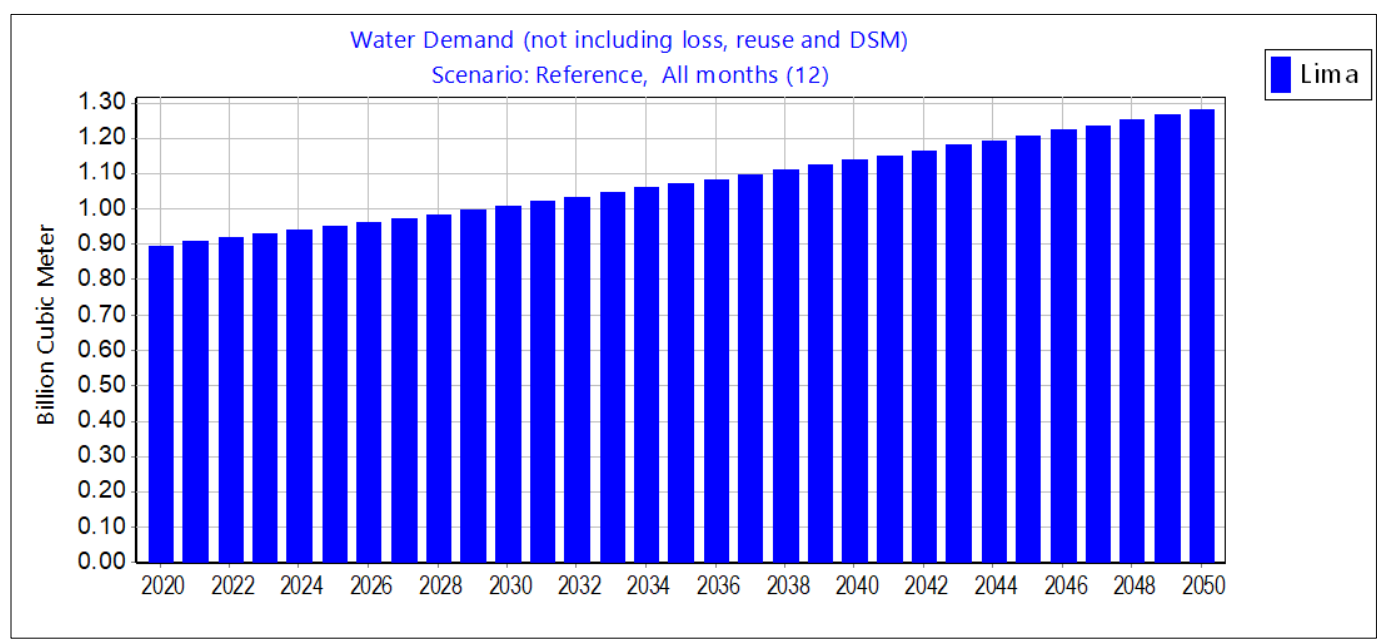

Fig. 7. Demand for water consumption MMC / year (2020-2050) Own source

\subsection{Hydrological Simulation Of Water Supply In The City Of Lima for The Period 2020-2050.}

Hydrological simulation is vital for the development of water supply projects, because it allows us to envision the future from the point of view of mathematical projection. The procedure that most promises in the application of computers to the hydrological basin is the simulation, that is, the representation in the computer, of a hydrological system by another mathematician that can reproduce the behavior of the natural system [10].

Currently, the city of Lima has a water deficit of $182 \mathrm{MMC} /$ year and a coverage of $81.8 \%$; in the short term (2025) the deficit will increase to $231.4 \mathrm{MMC} /$ year and coverage of $77.9 \%$; In the medium term the deficit will rise to $309 \mathrm{MMC} /$ year and a coverage of $70.5 \%$ and in the long term (2050) the deficit will increase to 510.1 MMC / year and the coverage will decrease to 62.1\%. Relevant details are presented in Table 6 and Figures 8 and 9.

Table 6. Water balance in the periods (2020-2050). Own source

\begin{tabular}{lcccc}
\hline Description & $\begin{array}{c}\text { Hydraulic offer } \\
\text { (MMC / year) }\end{array}$ & $\begin{array}{c}\text { Water demand } \\
\text { (MMC / year) }\end{array}$ & Coverage (\%) & $\begin{array}{l}\text { Water deficit } \\
\text { (MMC / year) }\end{array}$ \\
\hline Current (2020) & 730.20 & 892.30 & 81.80 & 182 \\
Short term (2025) & 712.52 & 929.23 & 77.90 & 231.40 \\
Medium term (2035) & 753.10 & 1048.70 & 70.50 & 309 \\
Long term (2050) & 759.3 & 1209.80 & 62.10 & 510.10
\end{tabular}




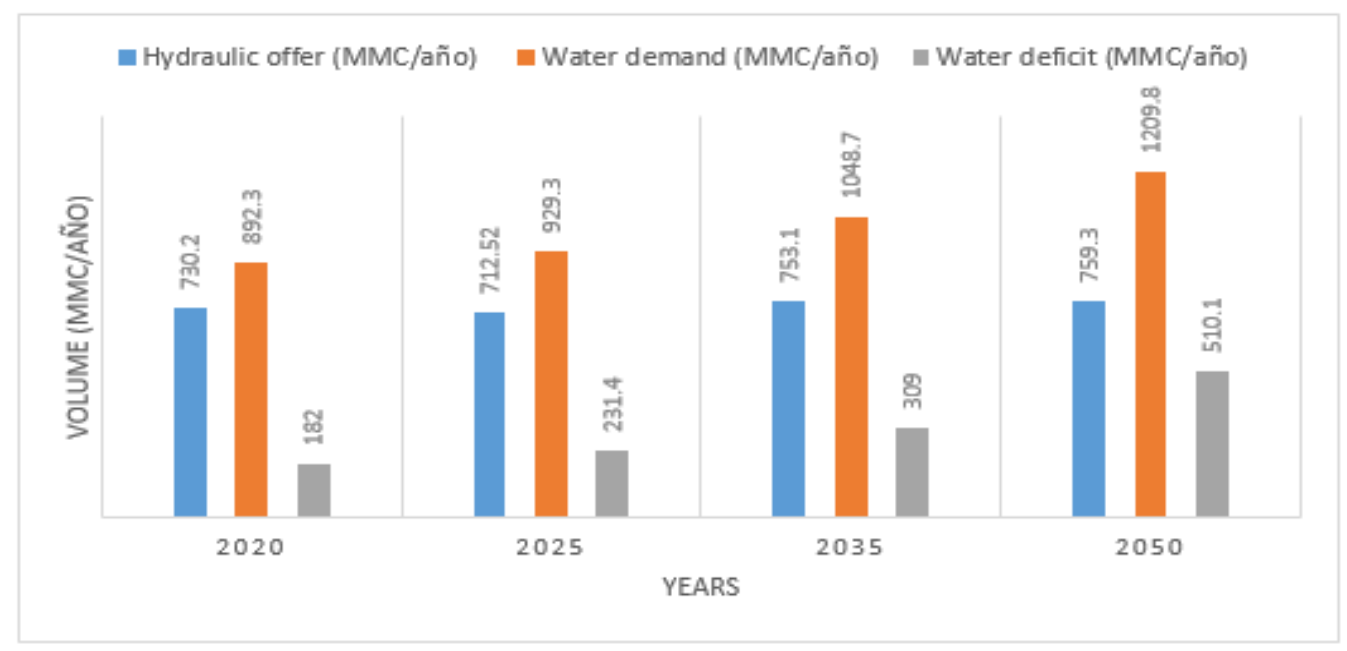

Fig. 8. Water balance of MMC / year 2020-2050 Own source

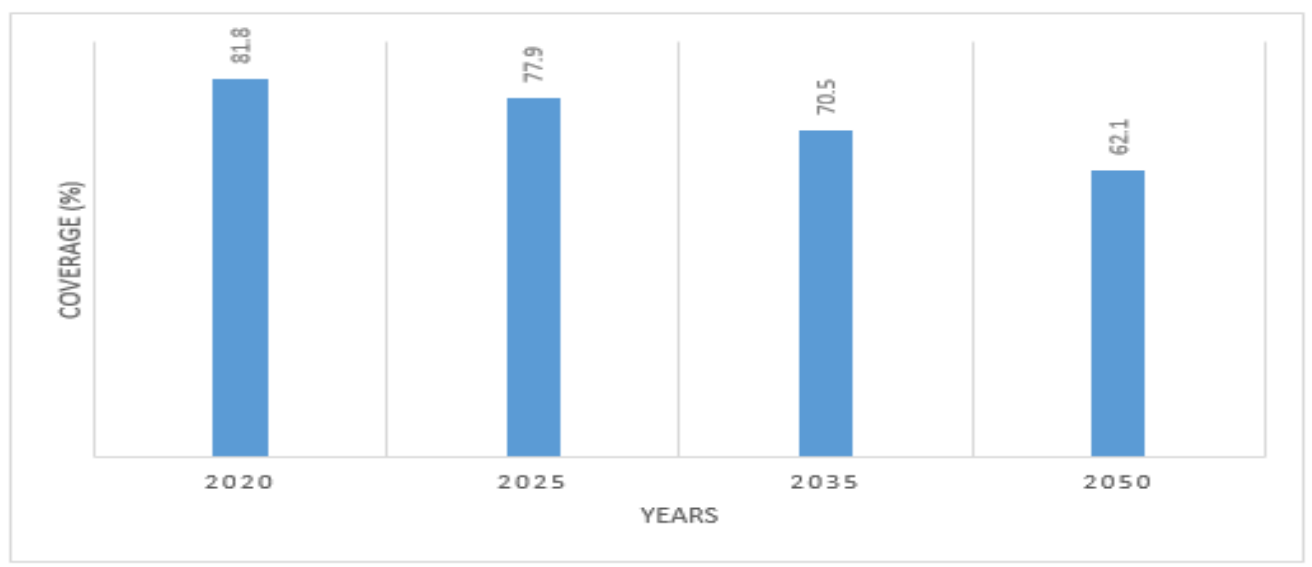

Fig. 9. Water coverage (\%) 2020-2050 Own source

\subsection{Hydrological simulation of water supply to the city of Lima with contribution from the projects Marcapomacocha II and IV for the years 2035 and 2050.}

If by action of the Peruvian Government, the Macapomacocha II project were to come into operation in 2035, the water deficit would be reduced to 267.9 MMC / year and coverage could be increased to $74.8 \%$; And if the Macapomacocha V project were to come into operation in 2050, the water deficit would be reduced to 410.2 MMC / year and the coverage would rise to $66.01 \%$, as detailed in Table 7.

Table 7. Water balance considering the Macapomacocha II and V projects. Own Source

\begin{tabular}{lcc}
\hline Years & 2035 & 2050 \\
\hline Project & Macapomacocha II & Macapomacocha \\
Water deficit (MMC / year) & 267.9 & 410.20 \\
Coverage (\%) & 74.80 & 66.01
\end{tabular}


In Table 8, the comparison of the water deficit for population use in the city of Lima is presented, taking into account the current scenario and the contributions of the Macapomacocha II and V project and in figure 10 its respective graph is presented.

Table 8. Comparison of the simulated scenarios in the WEAP platform for the 2020-2050 periods of the Water Deficit (MMC) .Own source

\begin{tabular}{cccc}
\hline Description & \multicolumn{2}{l}{$\begin{array}{c}\text { Water deficit (MMC / } \\
\text { year) }\end{array}$} & $\begin{array}{c}\text { Water deficit (MMC / year) } \\
\text { Water deficit (MMC / } \\
\text { year) }\end{array}$ \\
\hline Projects & $\begin{array}{c}\text { Simulation projection } \\
\text { (Brand I, III and IV) }\end{array}$ & $\begin{array}{c}\text { Simulation projection (Brand I, III Simulation projection (Brand I, III } \\
\text { and IV) + (Brand III) }\end{array}$ & $\begin{array}{c}\text { Sind IV) + (Brand III) + (Brand V) } \\
\text { and }\end{array}$ \\
\hline & & & 182 \\
2020 & 182 & 182 & 231.4 \\
2025 & 231.4 & 231.4 & 267.9 \\
2035 & 309 & 267.9 & 410.2 \\
2050 & 510.10 & 442.3 &
\end{tabular}

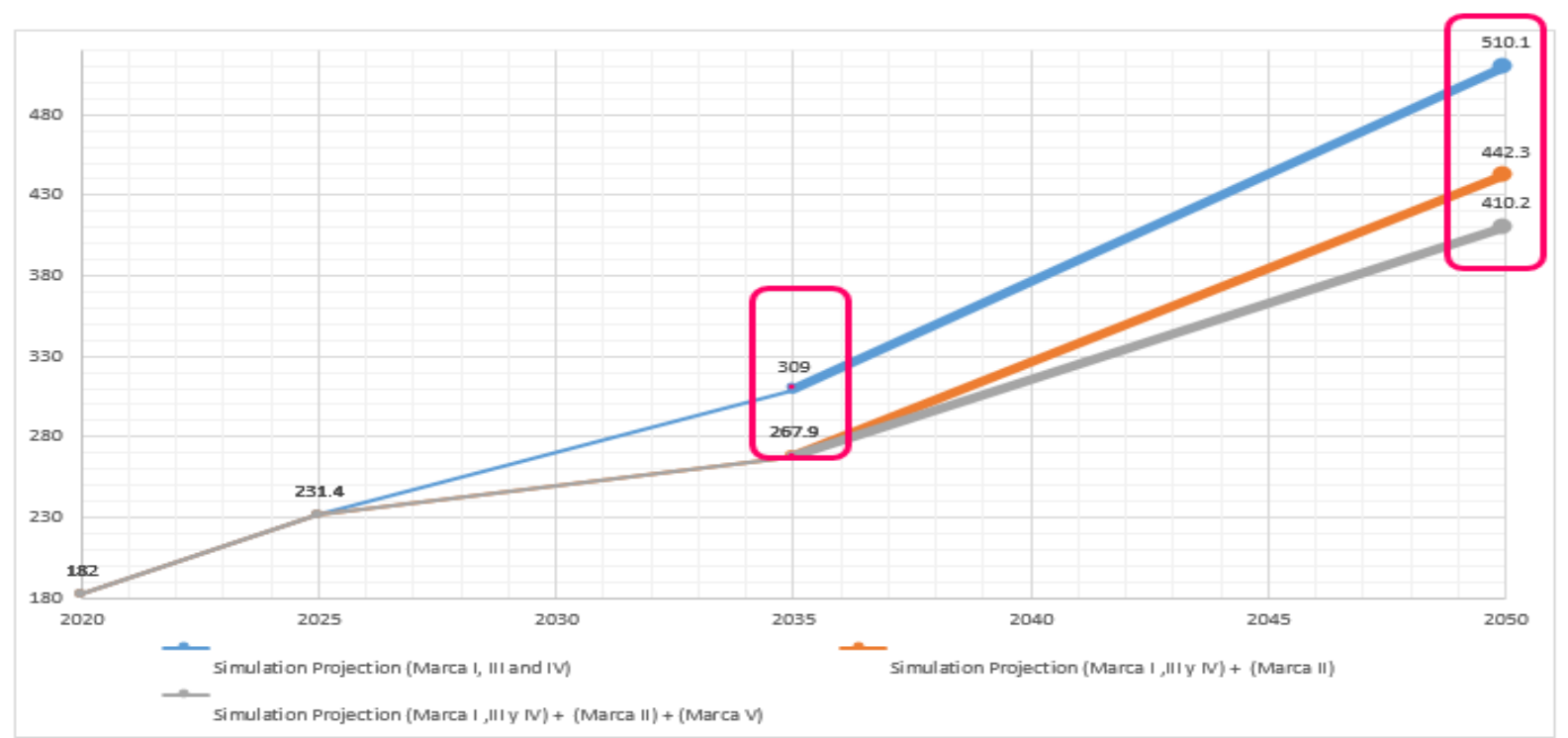

Fig. 10. Comparison of the annual water deficits (MMC) of the Macapomacocha I, II, III, IV and V projects. Own source

\section{Discussions and Conclusions}

From the simulation carried out on the WEAP platform, it is concluded that the current population of the city of Lima (year 2020) is 9,830,993,666 inhabitants and a water demand of 897.1 MMC / year, for the short term (2025) the population will be 10,435,181 inhabitants and a water demand of 952.2 MMC / year, for the medium term (2035) the population will be $11 ' 757,232$ inhabitants and a water demand of 1072.8 MMC / year and for the long term ( 2050) will increase to 14'060,889 inhabitants and the demand for water will grow to $1283.1 \mathrm{MMC} /$ year, which means that each year the demand for water increases by a volume of $12.45 \mathrm{MMC}$ / year equivalent to $0.395 \mathrm{~m} 3 / \mathrm{s}$.

The water supply has been simulated for the different scenarios, and by 2020 there is a water supply of $730.2 \mathrm{MMC} /$ year and they are contributions from the Macapomacocha Projects (I + III + IV), for the short term 2025 the supply of water could be $712.52 \mathrm{MMC}$ / year due to the presence of dry years and there will be no additional contribution due to the lack of new hydraulic works, for the medium term (2035) the water supply could be increased to $753.1 \mathrm{MMC} /$ year by the contributions from the Macapomacocha II Project and for the long term (2050). The water supply could be increased to 759.3 $\mathrm{MMC} /$ year by the contributions from the Macapomacocha V Project.

Currently (2020), the city of Lima has a water deficit of $182 \mathrm{MMC} /$ year and a coverage of $81.8 \%$, in the short term 
(2025), the water deficit will increase to 231.4 MMC / year and coverage it will decrease to $77.9 \%$ due to the lack of new hydraulic works; in the medium term (2035) the water deficit will increase to $309 \mathrm{MMC} /$ year and coverage will decrease to $70.5 \%$; and for the long-term scenario (2050), the deficit will increase to 510.1MMC / year and coverage will decrease to $62.1 \%$, these results are very worrying, because the long-term water supply would be reduced to a provision of $54 \mathrm{~m} 3 /$ inhabitant / year equivalent to $147 \mathrm{lt} / \mathrm{inhabitant} /$ day, which is a much lower module than $250 \mathrm{lt} / \mathrm{inhabitant} /$ day established by the Ministry of Housing and Construction of the Government of Peru.

Faced with this future of water deficit, it was simulated that in 2035 the Macapomacocha II project could start its operation with a contribution of $4 \mathrm{~m} 3 / \mathrm{s}$ in the dry period from May to December and the water deficit could be reduced to 267.9 MMC / year and coverage would increase to 74.8\%; Likewise, the hydrological simulation was also carried out, considering the contributions of the Macapomacocha V project, which could come into operation in 2050, with a contribution of $1.8 \mathrm{~m} 3 / \mathrm{s}$, and will help reduce the water deficit to 410.2 MMC / year and coverage would increase to $66.01 \%$

\section{Acknowledgements}

Our most sincere thanks to our alma mater from the University of Applied Sciences, for having provided us with the knowledge of this wonderful career; to the company BESCO SAC, JEF SAC and the District Municipality of Lince for opening their doors in the workplace, which gave us a lot of knowledge of this beautiful career and to our teachers, advisors, family and friends for being part of our professional development already Our teacher, Ing. David Maldonado Carrasco, may he rest, who gave us all his support and teaching in our professional stage and beautiful career.

\section{References}

[1] Jaramillo, María Fernanda, Galvis, Alberto and Sabas, Carlos (2016). "Integration of weap and qual2k models for the simulation of water quality from surface sources. Case study: La Vieja river basin, Colombia". Population growth and climate variability, pp 1-11.

[2] Andrés, Abrador, Juan, Zúñiga and Jonathan Romero. (2016). "Hydrological simulation of the potential impacts of climate change in the Aipe river basin in Huila, Colombia". Ibeoamerican Magazine of Water, pp. 1-14.

[3] Chow V, MaidmentD.R. And MaysL.W. (1994). "Applied Hydrology". McGraw Hill, 580 pp1-12.

[4] Collas Chávez Manuel Elias (2016). "Hydrological-economic analysis of current and projected dam alternatives in the Locumba Basin-Tacna Region. Doctoral thesis. Jorge Basadre National University.

[5] Escobar, M., Purkey, D., Pouget, JC, Suarez, W., Condom, T. and Ramos, C. (2008). "Construction of the Weap model of the Rio Santa." Progress report.

[6] World Meteorological Organization. "Hydrology - From measurement to hydrological information". WMO-N ${ }^{\circ} 168$. Sixth edition. 2011. Volume I.

[7] National Water Authority - Lima (2010). "Hydrological study and location of the hydrometric stations network".

[8] Weap Methodological Guide 2009. "Hydrological modeling and water resources with the Weap model. Center for Global Climate Change. pp. 1-86.

[9] Stockholm Environment Institute. (Febrary 2009). " Weap Water Evaluation and Planning system”. Tutorial.

[10] Ray k. Linsley, Jr., Max a. Kohler. (1977).! Hydrology for engineers". Latinoamericana, sa Editorial Mcgraw-hill Bogotá Colombia. 